\title{
Mesoscale structures in the transition zone: Dynamical consequences of boundary layer activities
}

\author{
David A. Yuen ${ }^{1}$, Laszlo Cserepes $^{2}$, and Brigit A. Schroeder ${ }^{1}$ \\ ${ }^{1}$ Department of Geology and Geophysics and Minnesota Supercomputer Institute, University of Minnesota, Minneapolis, MN 55415-1227, U.S.A. \\ ${ }^{2}$ Geophysical Department, Eötvös University, H-1083 Budapest, Hungary
}

(Received April 2, 1998; Revised September 10, 1998; Accepted October 20, 1998)

\begin{abstract}
Recent geophysical evidence from seismology, mineral physics, viscosity inversion shows that the mantle between 400 and $1000 \mathrm{~km}$ is extremely complicated, with intermediate scale structures present regionally as seismic reflectors under the $660 \mathrm{~km}$ discontinuity and bent plume-like structures under the transition zone. We have studied the dynamics of the transition zone with two models, an axisymmetric spherical-shell (2-D) model with a horizontally averaged temperature- and pressure-dependent viscosity and a 3-D Cartesian model with a depth-dependent viscosity. Two mantle phase transitions have been employed in both models. Results of the 2-D axisymmetric model show that the interaction of the lower mantle plumes with the transition zone can result in a horizontal channel flow right underneath the $660 \mathrm{~km}$ and in the birth of secondary plume some distance away from the lower mantle plume. The strength of the secondary plume increases in strength with larger viscosity contrast across the $660 \mathrm{~km}$ discontinuity. In the 3-D model we have found that with the presence of a second low viscosity zone somewhere between 660 and $1000 \mathrm{~km}$, many secondary instabilities are developed in the second asthenosphere and the mesoscale thermal structure developed can become quite complex. Many small-scale plumes can emanate from the transition zone. Occasionally a very large plume burst, with a near-surface radius exceeding $1000 \mathrm{~km}$, can develop from the hot lower-mantle material trapped in the second asthenosphere. Both the viscosity and the phase transition structure between $660 \mathrm{~km}$ and $1000 \mathrm{~km}$ can exert a significant influence on the plume distribution and cause singular plume eruption events in the upper mantle. Plume instabilities originating below the $660 \mathrm{~km}$ discontinuity in the western Pacific might have launched a large hot upwelling into the upper mantle, thus precipitating the massive flood basalt volcanism in the Ontong-Java region.
\end{abstract}

\section{Introduction}

It has long been recognized (e.g. Birch, 1954; Ringwood, 1982) that the transition zone and the region extending down to $1000 \mathrm{~km}$ plays an important role in governing the dynamics of the Earth's mantle and its thermal evolution (Steinbach et al., 1993; Breuer and Spohn, 1995; Allegre, 1997). Recently there have been several important developments in seismology from anisotropy (Montagner and Kennett, 1996; Vinnik et al., 1997), seismic phase analysis (Kawakatsu and Niu, 1994; Le Stunff et al., 1995; Niu and Kawakatsu, 1997; Castle and Creager, 1998) and tomography (Obayashi et al., 1995; Widiyantoro and van der Hilst, 1996; Zhou, 1996; Widiyantoro, 1997) which reveal layered structures with sharp reflective properties from a depth of $800 \mathrm{~km}$ down to around 1000 to $1100 \mathrm{~km}$ under some regions in the Pacific. Bent plume-like structures have also been visualized in recent tomographical models by Bijwaard and Spakman (1998) and Bijwaard et al. (1998). Using arguments drawn from mineral physics, Karato (1998) has pointed out the potential important relationship between seismic anisotropy in the transition zone and the shear flow in the boundary layer under the $660 \mathrm{~km}$ seismic discontinuity. Both laboratory (Bercovici and Mahoney, 1994; Griffiths et al., 1995; Guillou-Frottier et

Copy right $(\mathrm{C}$ The Society of Geomagnetism and Earth, Planetary and Space Sciences (SGEPSS); The Seismological Society of Japan; The Volcanological Society of Japan; The Geodetic Society of Japan; The Japanese Society for Planetary Sciences. al., 1995) and numerical experiments (Davies, 1995; Christensen, 1996; Nakakuki et al., 1997; Olbertz et al., 1997; Steinbach and Yuen, 1997; Cizkova and Cadek, 1997; Brunet and Machetel, 1998) have revealed the complicated dynamics in the transition zone region, caused by impinging plumes from the lower mantle and by slab interaction due to surface trench migration. Most of the focus has been directed at the endothermic nature of the phase transition at $660 \mathrm{~km}$ depth and not much attention has been devoted on the underlying viscosity structure below this depth. All of these recent efforts have strongly underscored the multidisciplinary nature of the transition-zone dynamics.

Mantle viscosity structure between 400 and $1000 \mathrm{~km}$ is extremely complex (e.g. Forte et al., 1994). Recently there is an accumulating evidence from the inversion of geoid anomalies, which argue for the plausible existence of a low viscosity zone under the $660 \mathrm{~km}$ discontinuity (Ravine and PhippsMorgan, 1996; Cadek et al., 1997; Kido and Cadek, 1997; Kido et al., 1998; Quinn and McNutt, 1998). Such a low viscosity zone may be due to the grain-size reduction across the phase transition (Riedel and Karato, 1997) and to the dynamics of partial-layered convection in which the wide lateral flow of hot lower-mantle plumes impinging at the internal boundary layer at $660 \mathrm{~km}$ may conceivably cause a low viscosity zone under the transition zone because of the temperature dependence of mantle rheology. This second asthenosphere may have similar origins to the top astheno- 
sphere near oceanic ridges, which may be caused by the hot horizontal flow coming out from the rising sheet-like structure in high Rayleigh number convection (Olson and Corcos, 1980). Three-dimensional numerical modelling of mantle convection with such a second asthenosphere under an endothermic phase change at $660 \mathrm{~km}$ depth (Cserepes and Yuen, 1997) has shown the important effects associated with the channel-flow and secondary instabilities developed in the top part of the lower mantle. Recent work by Cserepes et al. (1998) has further emphasized the significant effects caused by the presence of this second asthenosphere, interacting with the $440 \mathrm{~km}$ phase change.

From a fluid dynamical standpoint, the presence of any sort of internal boundary layer or regions with some sort of flow blockage would likely to produce secondary instabilities, such as diapirs or secondary upwellings (Liu et al., 1991; Steinbach and Yuen, 1997). The objective of this paper is to employ large-scale numerical modelling as a tool to demonstrate some new ideas about the boundary layer dynamics potentially present in the zone between 660 and $1000 \mathrm{~km}$ depth. Geochemists, in fact, have often raised the issue of some source material being able to be derived from this particular portion of the top lower mantle (Allegre and Turcotte, 1985; White and McKenzie, 1989; Fitton et al., 1997). In this paper we will illustrate that secondary upper-mantle plumes emanating from a primary lower-mantle plume, as suggested previously (Maruyama, 1994), are indeed dynamically feasible. Here we hope to convey to researchers in other fields the different possibilities of dynamical mesoscale features in the transition zone, which would help them to interpret better their own data.

\section{Description of the 2-D and 3-D Models}

To study the dynamics of mantle flow in the transition zone, we have employed two different types of models: (1) a two-dimensional axisymmetric, spherical-shell model and (2) a three-dimensional Cartesian model with an aspect-ratio of $4 \times 4 \times 1$, with unity being the depth. With model (1) we can investigate closely the interaction between the mesoscale flow from the transition zone in the presence of the global circulation. On the other hand, for examining the birth of small-scale plumes and downwellings in the transition zone, we have employed model (2) which is a local Cartesian model in 3-D with high spatial resolution.

\subsection{Two-dimensional spherical-shell model}

The 2-D spherical-shell model is based on the extendedBoussinesq approximation (Christensen and Yuen, 1985; Steinbach et al., 1989) in which the background density is constant and has two phase transitions built-in at 400 and $660 \mathrm{~km}$ depth with the enhanced thermal expansivity approach for simulating the effects of phase transitions (Christensen and Yuen, 1985). The phase transitions are the olivine to spinel and the spinel to perovskite transition with the respective Clapeyron slopes of $+3 \mathrm{MPa} / \mathrm{K}$ and $-3 \mathrm{MPa} / \mathrm{K}$ and density changes of $8 \%$ and $10 \%$. The radius of the Earth is set to be $6380 \mathrm{~km}$ and the radius of the core to $3480 \mathrm{~km}$. A depth-dependent background thermal expansivity, which decreases by a factor of 5 across the mantle (Chopelas and Boehler, 1992), is employed. An analytical form of this thermal expansivity can be found in Steinbach and Yuen (1994).
The thermal conductivity is constant. The dimensionless surface temperature $T_{0}$ is 0.2 and the surface dissipation number is 0.4 . A depth-dependent viscosity $\eta$ takes the dimensionless form:

$$
\eta=\exp \left(\frac{A}{T_{0}+\langle T\rangle}\right) \exp \left(\frac{-A_{0}}{T_{0}}\right)
$$

where in the upper mantle $A(z)=A_{0}$ and the bracket sign denotes an average over the latitude. In the lower mantle $A$ takes the form:

$$
A(z)=A_{0}\left\{1+\log \Delta \eta \frac{\left(T_{0}+\langle T\rangle\right) F(z)}{A_{0}}+A_{1} \frac{\left(z_{0}-z\right)}{z_{0}}\right\}
$$

where $z_{0}$ is $660 \mathrm{~km}, z$ is depth in $\mathrm{km}, \Delta \eta$ is the viscosity jump across the $660 \mathrm{~km}$ discontinuity, $A_{0}$, and $A_{1}$ are rheological parameters. The form of the upper mantle viscosity is not varied and the jump in viscosity $\Delta \eta$ takes place at the $660 \mathrm{~km}$ boundary (see Fig. 1(a)). The dimensionless surface temperature $T_{0}$, here taken to be 0.2 . And $F(z)$, applying only in the lower mantle, is

$$
F(z)=\frac{1}{2}\left\{1+\tanh \left(\frac{2\left(z-z_{0}\right)}{d}\right)\right\}
$$

and $d$, the width of the interface zone situated at $660 \mathrm{~km}$ depth, is taken to be $20 \mathrm{~km}$.

This form of the rheology is similar to that employed in van Keken and Yuen (1995) and Steinbach and Yuen (1998). Values of $A_{0}$ and $A_{1}$ are chosen such that a decrease of viscosity by a factor of 10,000 due to the temperature difference across the mantle alone and a factor of 40 increased due to the depth dependence of the viscosity from $660 \mathrm{~km}$ depth to the core-mantle boundary (CMB).

We have employed the stream-function and temperature formulation for solving the momentum and energy equations. The momentum equation is given by a fourth-order bi-harmonic equation in polar coordinates with the Rayleigh number being the control variable governing the buoyancy driving force, while the energy equation is a second-order partial differential equation in space and first-order in time with both the adiabatic and viscous heating terms included. Except for one case, there is no internal heating. The latent heat term in phase transition is simulated by the enhanced thermal expansivity in the adiabatic heating term. The sudden increase in the buoyant forces during a phase transition is modelled by the enhanced thermal expansivity (Christensen and Yuen, 1985) in the thermal buoyancy term in the bi-harmonic momentum equation. The equations can be found in Breuer et al. (1997). A sixth-order finitedifference method (Fornberg, 1990) has been employed. A description of this discretization scheme as applied to both two- and three-dimensional convection problems can be found in Larsen et al. (1997). In this study we have employed 160 points in the radial direction and 550 points along the tangential direction for the spherical-shell model. Table 1 summarizes the characteristics and physical parameters for the 2-D and 3-D models.

\subsection{Three-dimensional Cartesian model}

In the 3-D Cartesian model we have employed the anelastic-liquid approximation (Jarvis and McKenzie, 1980) 

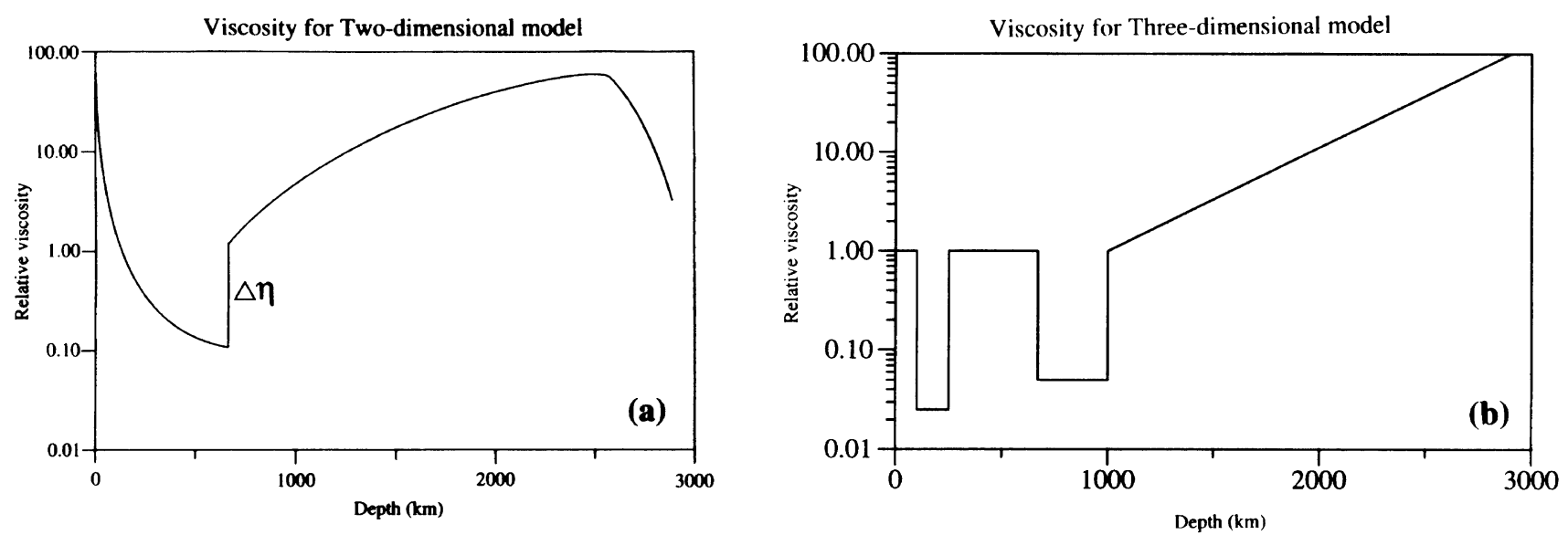

Fig. 1. Viscosity profiles used in the modelling: (a) The formula is given in Eq. (1) for this horizontally averaged temperature-dependent and depth-dependent viscosity and $\Delta \eta$ represents the viscosity jump at $660 \mathrm{~km}$ depth. This viscosity is used in the 2-D axisymmetric model. (b) The viscosity profile with two low viscosity zones used in the 3-D Cartesian model.

Table 1. Physical properties of the two models.

\begin{tabular}{lll}
\hline & 2-D & 3-D \\
\hline Thermal expansivity & depth-dependent & constant \\
Thermal conductivity & constant & constant \\
Viscosity & dependent on $\langle T\rangle$ and on depth & depth-dependent with two low viscosity zones \\
Background density & constant & depth-dependent \\
$400 \mathrm{~km}$ phase change & $P=0.05$ (based on surface values) & $P=0.05$ \\
$660 \mathrm{~km}$ phase change & $P=-0.06$ (based on surface values) & $P=-0.06$ \\
$1000 \mathrm{~km}$ phase change & - & $P=-0.03$ \\
Internal heating & only one case with 1.5 times chondritic value & - \\
\hline
\end{tabular}

in which the background density is a function of depth $z$. The viscosity is strictly depth-dependent (see Fig. 1(b) below). The effective thermal expansivity and compressibility vary strongly in the depth interval where each phase change occurs. The 3-D equations for thermal convection are solved by the poloidal potential, which automatically satisfies the continuity equation, and the temperature approach. The momentum equation for the poloidal potential $\Phi$ is a bi-harmonic equation (e.g. Travis et al., 1990) in which the inhomogeneous forcing terms contain both the thermal and phase transitional buoyant forces, while the energy equation is a partial differential equation for $T$ in time and space (Cserepes et al., 1988). The latent heat is treated in the same way as for the two-dimensional formulation, i.e. in the enhanced thermal expansivity. Also included are the adiabatic and viscous heating contributions. The background thermal expansivity, however, is a constant for the 3-D model, as is the thermal conductivity. A surface temperature $T_{0}$ of 0.1 is used along with a dissipation number $D$ of 0.5 . The background density variation is given by

$$
\rho=\exp \left(\frac{D z}{\gamma}\right) \exp \left(\sum_{k}\left(\frac{\Delta \rho}{\rho}\right)_{k} \chi_{k}\right)
$$

where $\gamma$ is the Grueneisen parameter, taken to be 1.4 , $(\Delta \rho / \rho)_{k}$ is the relative density jump across the $k^{\text {th }}$ phase change and $\chi_{k}$ is the phase function (e.g. Christensen and Yuen, 1985) in the $k^{\text {th }}$ transition zone. See Table 1 for additional details.

We have used a depth of $2900 \mathrm{~km}$ for the 3-D box with phase transitions at 400, 660 and $1000 \mathrm{~km} \mathrm{depth}$. The Clapeyron slopes and density changes for the phase transitions at 400 and $660 \mathrm{~km}$ depth are the same as in the 2-D model. The phase transition buoyancy parameters $P$ (e.g. Steinbach and Yuen, 1994) can be found in Table 1. The possible phase transition at $1000 \mathrm{~km}$ is endothermic and has a magnitude of the Clapeyron slope, which is the same as the spinel-perovskite transition but with half the density change. This hypothetical phase change has been imposed, because Kawakatsu and Niu (1994) have argued for such a Clapeyron slope to account for the variable depth of the $920 \mathrm{~km}$ discontinuity. From a mineralogical viewpoint, this discontinuity can be caused by various possibilities: a chemical boundary due to a sharp change in the partition coefficient of $\mathrm{Ni}$ and $\mathrm{Co}$ (Tschauner, 1997; Tschauner et al., 1998) or due to the garnet phase transition at these depths (O'Neill and Jeanloz, 1994; Kesson et al., 1995; Irifune et al., 1996). We have imposed 
this hypothetical phase transition at $1000 \mathrm{~km}$ to study its potential effects, acting in concert with the second asthenosphere, in producing mesoscale flows beneath the $660 \mathrm{~km}$ discontinuity. At the same time, this transition can also reinforce layering so that secondary plumes can be produced in the transition zone. The viscosity profile, shown in Fig. 1(b), has a low viscosity channel between 100 and $250 \mathrm{~km}$ and a second low viscosity channel between 660 and $1000 \mathrm{~km}$ depth. From $1000 \mathrm{~km}$ to the CMB, the viscosity increases exponentially by two orders in magnitude.

The momentum and energy equations have been solved numerically by a combined second-order finite-difference (vertical) and spectral (horizontal directions) method (Cserepes et al., 1988). For further details concerning the equations, we refer the reader to Cserepes and Yuen (1997) and Cserepes et al. (1998). The grid 3-D configuration used consists of $320 \times 320 \times 160$ points. Such a large grid is needed to capture all of the multiple-scale features produced within the complicated region between 660 and $1000 \mathrm{~km}$ depth. By putting enough points across this region, we can resolve the small secondary plumes developing there.

\section{Results}

In this section we will present results taken from both the axisymmetric (2-D) spherical-shell and the 3-D Cartesian models. These high-resolution simulations will aim to illustrate the different facets of the mesoscale dynamics generated in the transition zone and the region immediately below.

\subsection{Axisymmetric (2-D) spherical-shell model}

We begin with a case in which the averaged Rayleigh number of the purely basally heated spherical-shell system is $5 \times 10^{6}$. The averaged Rayleigh number is defined on the basis of the averaged viscosity and surface value of the other physical parameters. There is no viscosity contrast across the $660 \mathrm{~km}$ discontinuity. The run has been started from a case without the two phase transitions. About 80,000 timesteps (about 5 overturns in the upper mantle) have been taken to reach a statistically steady-state situation. Figure 2 shows a global shot along with a sequence of zoomed-in view of the plume-plume collision process (panel 1 and 2), leading to a laterally spreading hot region under the $660 \mathrm{~km}$ discontinuity. A rising secondary instability is observed in both panel 4 and the global shot at the bottom of Fig. 2. In panel 4 one also sees the juxtaposition of cold descending sheet overlying the hot spreading wings of the plume. Thus near the $660 \mathrm{~km}$ discontinuity a shear flow develops between the cold and hot boundary layers, which come respectively from the upper- and lower-mantle. Because of the nature of the horizontally averaged temperature-dependent viscosity (see Eq. (1)), there is no low viscosity zone developed under the $660 \mathrm{~km}$ discontinuity. We note from the bottom panel in Fig. 2 that in this Rayleigh number regime the style of mantle convection is not strictly layered. In some regions there is mass circulation through the $660 \mathrm{~km}$ phase change in the downwelling. The hot upwelling is blocked more by the $660 \mathrm{~km}$ phase change at this time instant.

The next case has a viscosity jump of a factor of 5 across the $660 \mathrm{~km}$ discontinuity. Figure 3 shows the case in which a viscosity contrast of 5 has been imposed across the transition. The averaged Rayleigh number is now decreased to
$2 \times 10^{6}$. The lower mantle plumes become thicker and there is a more violent interaction between the plume and the $660 \mathrm{~km}$ phase transition than for the case without the viscosity jump (Fig. 3). This nonlinear amplification mechanism is due to the viscosity jump (van Keken et al., 1992). This process is further enhanced by the release of latent heat from the perovskite to spinel transition and by the enhancement in the upward buoyancy during the phase transition of the denser to lighter phase. Again we note from the bottom panel that the style of mantle convection is not wholly layered. In some regions penetration of the flow across the $660 \mathrm{~km}$ boundary is easier.

Figure 4 shows the case with a viscosity jump of $20 \mathrm{im}$ posed across the $660 \mathrm{~km}$ discontinuity. The averaged Rayleigh number decreases now to $3 \times 10^{5}$. There is now a difference of more than an order in magnitude between the averaged Rayleigh number in the upper mantle and that in the lower mantle. This disparity in the Rayleigh numbers of the two systems causes a separation of scales between the upper and lower mantle convective flows. The lower mantle features become much greater in size, especially the large plumes. The plume widths are reduced upon crossing the $660 \mathrm{~km}$, because of the reduction by twenty fold in the viscosity. This gives rise to small scale instability rising at the edge of the wing of the plume (panel 1 and 2). We observe again there is a sharp thermal contrast between the horizontal cold boundary layer coming from a descending current in the upper mantle and the hot boundary layer from the bent lower-mantle plume. We note that the dark region near the bottom of the polar plume (bottom panel) has very high temperature, exceeding that at the CMB, thus suggesting some melting there (Helmberger et al., 1998). This local buildup of the temperature comes from the long-lasting viscous heating at the base of a relatively stationary plume.

Viscous dissipation yields important information about the thermo-mechanical state of mantle flow, whether or not some regions are severely deformed, as in the plume impingement process. From the viscosity distribution $\eta$ and viscous dissipation field $F$, one can calculate the second-invariant of the stress field $\tau$, with the relationship $\tau=\sqrt{\eta F}$. The secondinvariant of the stress tensor is a valuable diagnostic quantity for revealing the potential of seismic anisotropy induced by mantle flow (Ribe, 1992). Figure 5 shows the viscous dissipation distribution of the global frame shown in Fig. 4. Most of the dissipation takes place in the plume along the polar axis, since the polar region is the site for 3-D type of deformation, which produces much greater amount of dissipation than for motions off the polar axis. Strong viscous heating is observed near the $660 \mathrm{~km}$ discontinuity and also at the bottom of the plumes, which can help to cause localized melting at the base of plumes near the CMB (Garnero and Helmberger, 1996; Helmberger et al., 1998; Wen and Helmberger, 1998). Values of viscous heating surpassing 500 corresponds to around 50 times the chondritic heating value. With a greater contrast in the temperature-dependent viscosity, larger shear heating rates can be expected (Thompson and Tackley, 1998).

Plumes in the lower mantle with a steep viscosity gradient and subject to internal heating have been investigated by Zhang and Yuen (1996), who found that there was a non- 
No Viscosity Contrast

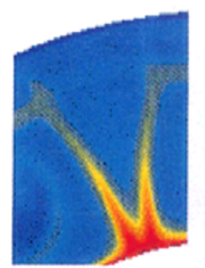

1

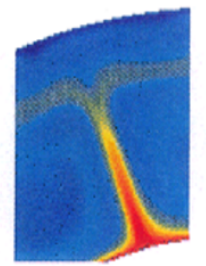

2

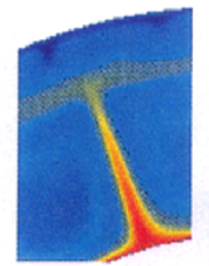

3

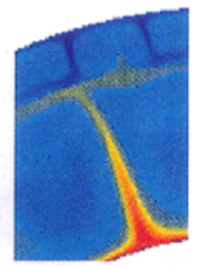

4

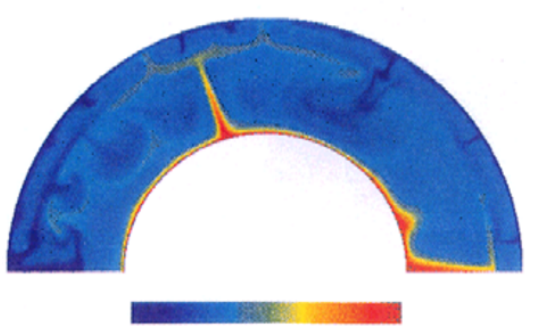

Fig. 2. Temperature fields of axisymmetric spherical shell convection with two phase transitions and a temperature- and pressure-dependent viscosity under the extended Boussinesq approximation. A sixth-order finite-difference method has been employed. Viscosity is given in Fig. 1(a). Five snapshots in sequence are shown with the global shot representing the final view. Time intervals are 4 million years between the frames. The averaged Rayleigh number of the entire system is about $5 \times 10^{6}$. There is no internal heating.

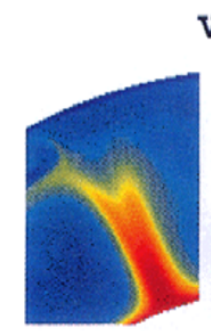

1
Viscosity Contrast 5

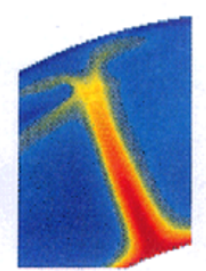

2

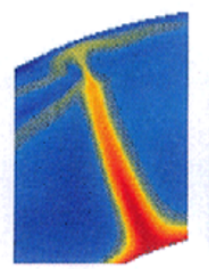

3

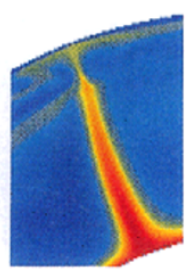

4

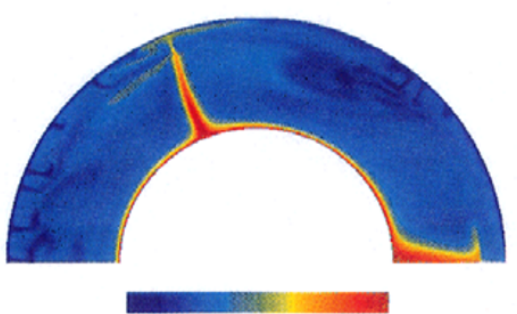

Fig. 3. The same as for Fig. 2 except there is a viscosity jump of a factor of 5 at the $660 \mathrm{~km}$ discontinuity. Time intervals are around 2 million years apart. The averaged Rayleigh number is around $2 \times 10^{6}$.

linear feedback between internal-heating and viscous dissipation, which further enhanced the plume strength. These models did not include any phase transitions. In Fig. 6 we show a sequence of the zoomed-in snapshots of the temperature and viscous heating fields of an internally heated case (strength being 1.5 times the chondritic radioactive abundance) with a viscosity jump of 20 across the $660 \mathrm{~km}$ discontinuity. The basal heating and internal heating averaged Rayleigh numbers are respectively $4 \times 10^{5}$ and $8 \times 10^{6}$. The

Viscosity Contrast 20

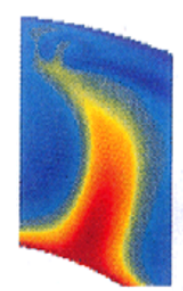

1

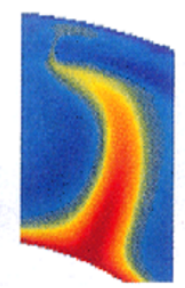

2

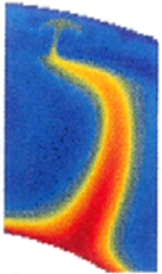

3

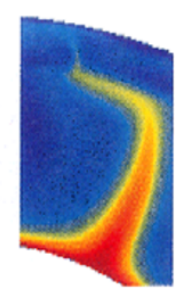

4

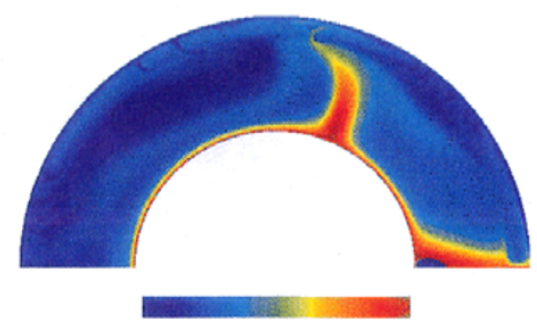

Fig. 4. The same as for Fig. 2 except there is a viscosity jump of a factor of 20 across the endothermic phase change. Time intervals are around 1.5 million years apart. The averaged Rayleigh number is $3 \times 10^{5}$.

time sequence is from top to bottom. We observe that there is a large megaplume developed in the lower mantle, which rises toward the $660 \mathrm{~km}$ phase change and is then deflected. Secondary rising instabilities are produced by the interaction of the large plume with the endothermic phase change. There can be a large separation, more than $1600 \mathrm{~km}$, between the major plume under the lower mantle and the surface hotspot produced by the secondary plume (bottom row). Maximum peaks of viscous heating (right column) can be found at the bottom of the lower-mantle plume, under the transition zone and right under the lithosphere. At all of these sites it is conceivable that one may find significant amounts of stress focusing and perhaps some traces of seismic anisotropy developed.

\subsection{Three-dimensional Cartesian model}

Previous results of this Cartesian model with one endothermic phase transition and two low viscosity zones can be found in Cserepes and Yuen (1997). This particular 3-D model, which we will focus here, is a new result. It is heated from below (i.e. no internal heating) and has two low viscosity zones and three phase transitions, one exothermic at $400 \mathrm{~km}$ depth and the other two exothermic transitions at 660 and $1000 \mathrm{~km}$ depth. This model at a surface Rayleigh number of $2 \times 10^{7}$ was started from an already convecting solution with 2 phase transitions and 2 low viscosity zones (Cserepes et al., 1998) and was integrated in time, until the solution became statistically steady-state. We proceed now to examine various aspects of this 3-D flow, going from the global view to detailed images of the secondary plumes in the upper mantle. The multiplicity of spatial scales in the flow demands this kind of detailed and high-resolution scientific visualization.

In Fig. 7 we show two global views of the $4 \times 4 \times 1$ convection configuration by using 3 isotherms, $T=0.2,0.5$ and 0.8 as the isosurfaces in the visualization. The temperature across the whole mantle layer is assumed to be around 


\section{Viscous Dissipation: viscosity Contrast 20}

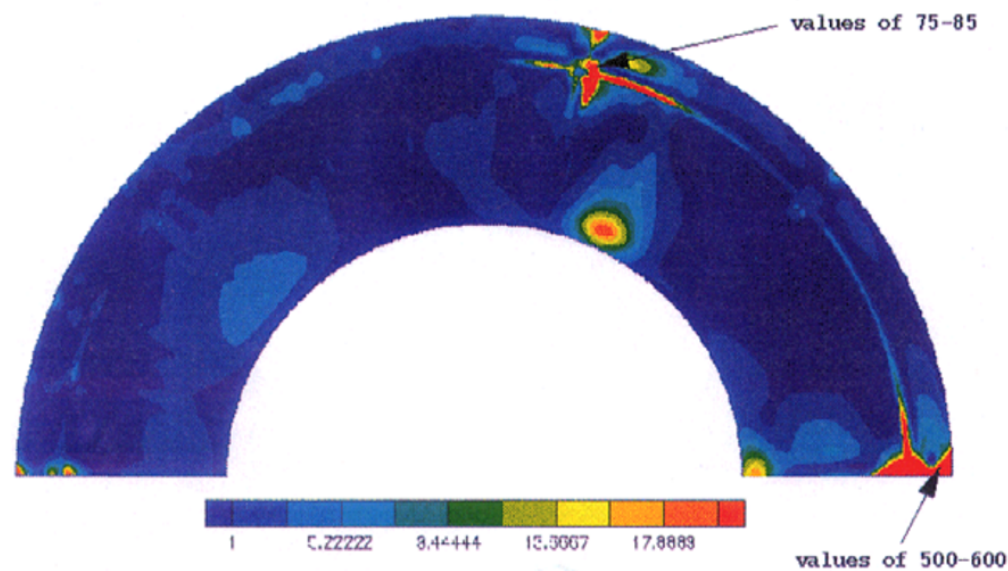

Fig. 5. The viscous heating distribution associated with the last (global) frame in Fig. 4. Regions of intense viscous heating are shown by the localized features in the transition zone by the plume impingement and at the bottom of the lower mantle upwellings near the CMB.
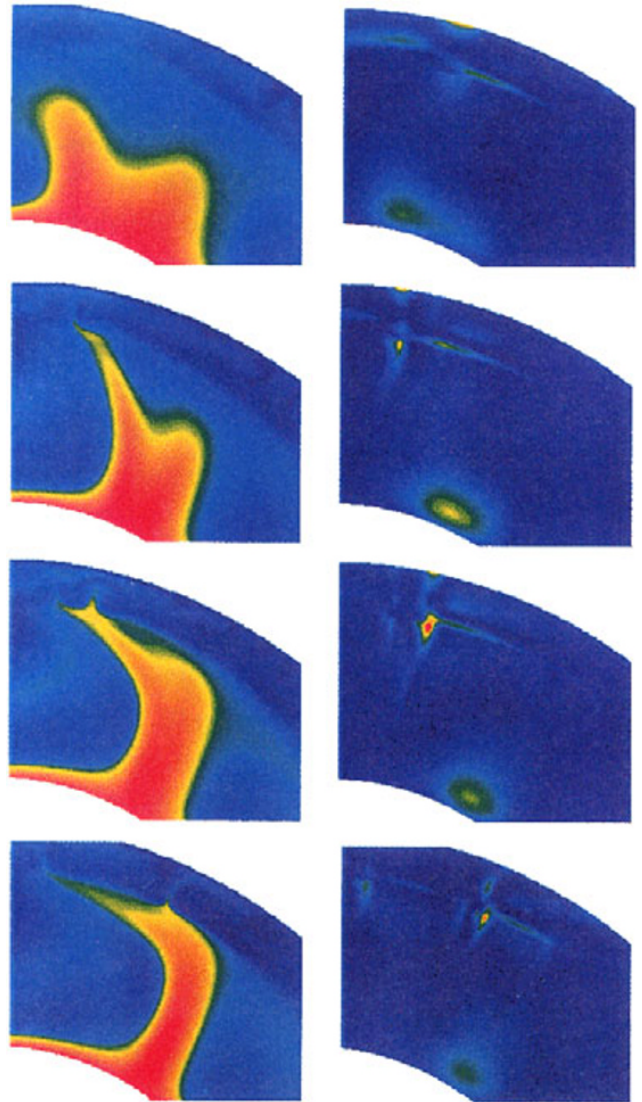

Fig. 6. The zoomed-in views of both the temperature of a large lower-mantle upwelling (left) and the associated shear-heating distribution (right). The case has the same viscosity jump of a factor of 20 as in Fig. 4 but has an internal heating strength, which is 1.5 times the chondritic radioactive heating value.
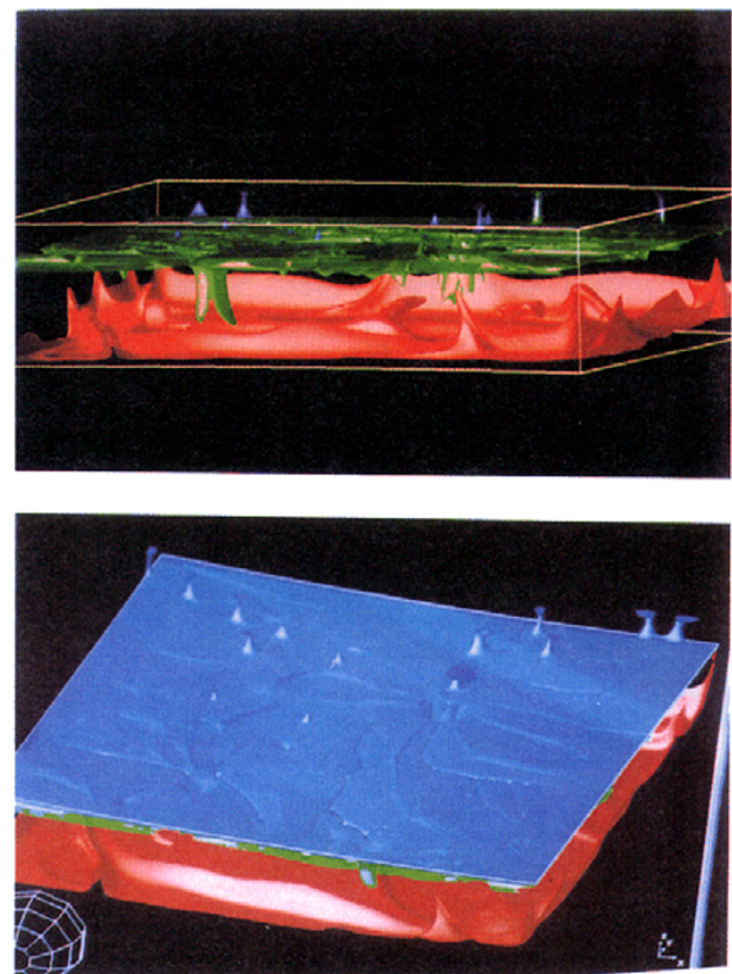

Fig. 7. Global views of three-dimensional simulations with aspect-ratio $4 \times 4 \times 1$, with unity being the depth and with basal heating. The model has two low viscosity zones (see Fig. 1(b)), the first between 100 and $250 \mathrm{~km}$ and the second between 660 and $1000 \mathrm{~km}$ depth with a decrease respectively of 40 and 20 . The grid configuration is $320 \times 320 \times 160$ grid points with second-order spatial accuracy in the vertical and spectral accuracy in the horizontal. The solution has been integrated beyond the transient stage and has developed many overturns. The three temperature isosurfaces correspond to $T=0.3,0.5$ and 0.8 . The zone between 660 and $1000 \mathrm{~km}$ is the place where many small-scale features are concentrated. Top and bottom panels represent views from the side and from the top respectively. 
$3500 \mathrm{~K}$. The style of convection shown here leans more toward layered convection than whole mantle flow. One is struck immediately by the complexity of the thermal features in the region right below the transition zone, which is about a quarter of way down from the top. There is also a disparity of scales between the upper and lower mantle, due to the much higher viscosity in the lower mantle. The averaged Rayleigh number of the mantle below $1000 \mathrm{~km}$ is around $10^{5}$, as compared to a much higher averaged Rayleigh number in the top $660 \mathrm{~km}$ of the mantle. The plumes in the upper mantle are more transient than the lower-mantle structures and move about above the $660 \mathrm{~km}$ discontinuity. The descending flow into the lower mantle is columnar in form, because there is no imposed surface velocities at the top of the convecting cell (Bunge and Richards, 1996). It is interesting to note that the many plumes emanate from the $660 \mathrm{~km}$ surface but none come directly from the lower mantle. These plumes are supported by a finite temperature increase across the $660 \mathrm{~km}$ phase transition. Some of these plumes, which are situated in the rear of the box, are hotter than others, as shown by the second isosurface $(T=0.5)$ almost reaching the surface. The close-up views of two of these strong plumes are displayed in Fig. 8. Here one can discern the different degree of upward penetration by the $T=0.5$ isosurface, embedded within the $T=0.3$ surface, which delineates the general shape of the rising secondary plume in the upper mantle.
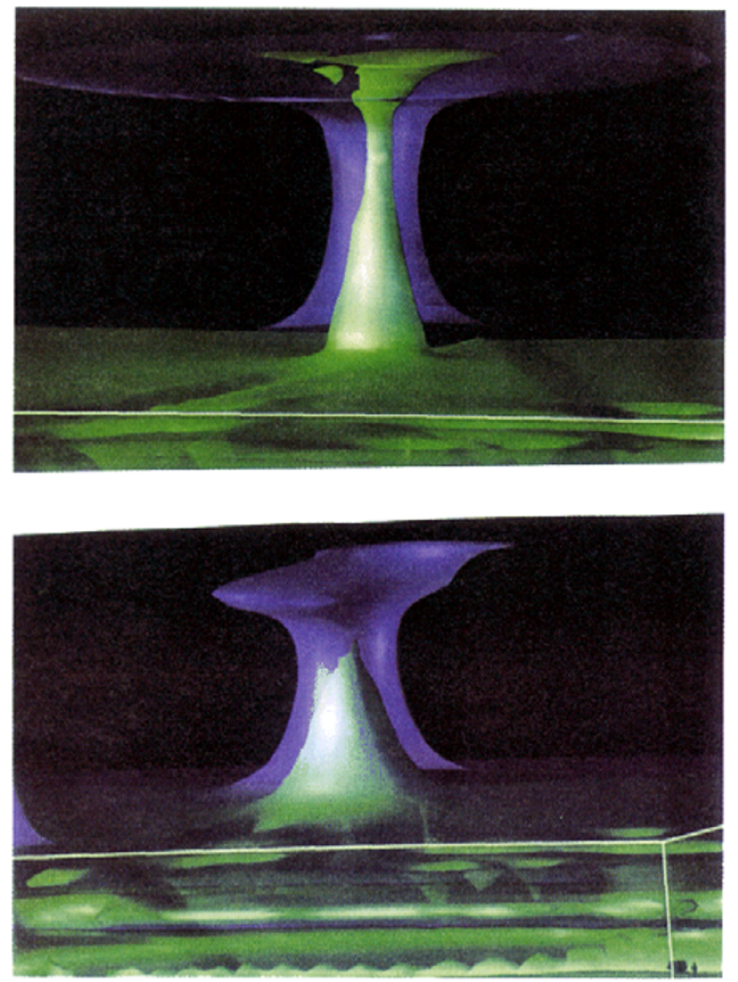

Fig. 8. Zoomed-in views of two different upwellings originating from the $660 \mathrm{~km}$ discontinuity. The two temperature isosurfaces represent $T=0.3$ (outer surface) and $T=0.5$ (inner surface). The hot inner column represents material drawn directly from the second asthenosphere under the $660 \mathrm{~km}$ discontinuity. There is a pool of hot mass with $T=0.5$ right under the spinel-perovskite phase change. Same time frame as in Fig. 7.
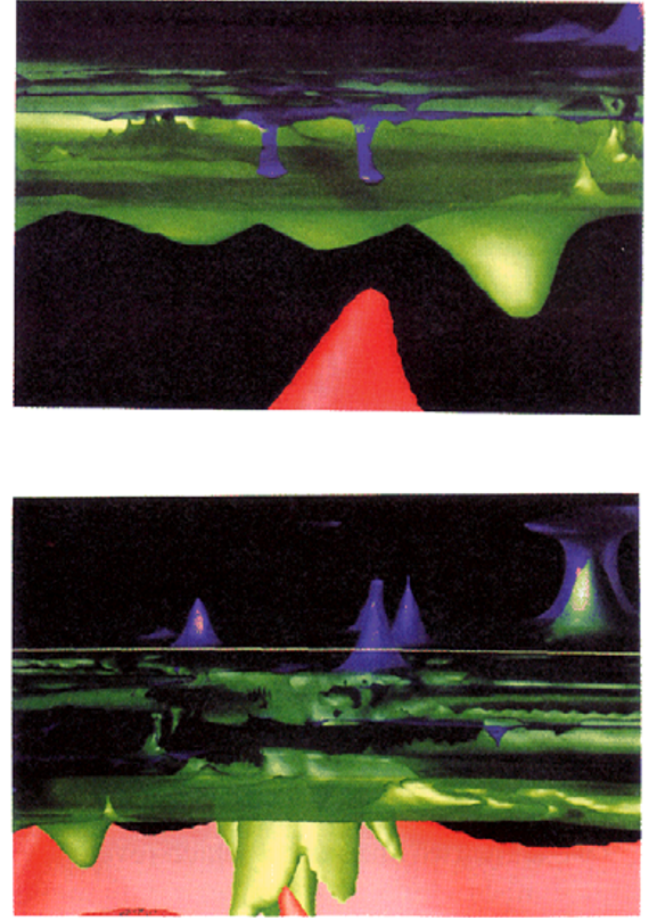

Fig. 9. Zoomed-in view of the transition zone region between 660 and $1000 \mathrm{~km}$. Here one notices that small sinking instabilities (top panel) are associated with the $T=0.3$ surface, as contrasted with the upwelling carrying the same temperature value upwards in the bottom panel. The plume in the background with the two isosurfaces is the same plume in the bottom panel of Fig. 7. Same time step as in Fig. 7.
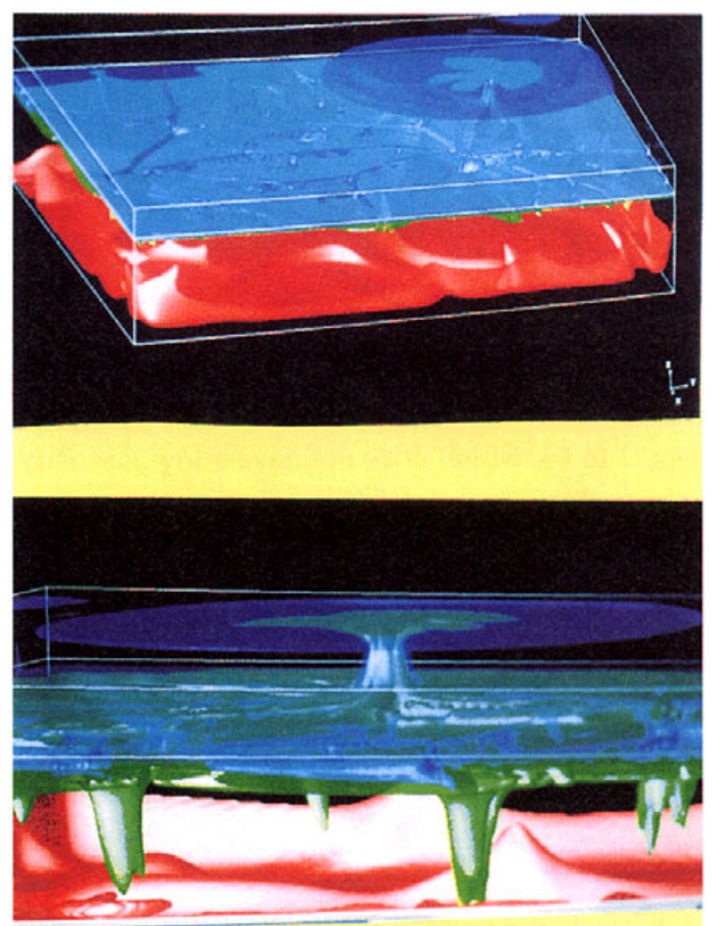

Fig. 10. Snapshots showing the megaplume bursting event. This event took place some time later (around $150 \mathrm{Myrs}$ ) than the views displayed in Figs. 7 to 9. The second set of horizontal lines mark the $660 \mathrm{~km}$ discontinuity. We note that the width of the megaplume head, around $2000 \mathrm{~km}$, can be estimated from comparing to the depth of the box, which is $2900 \mathrm{~km}$. 


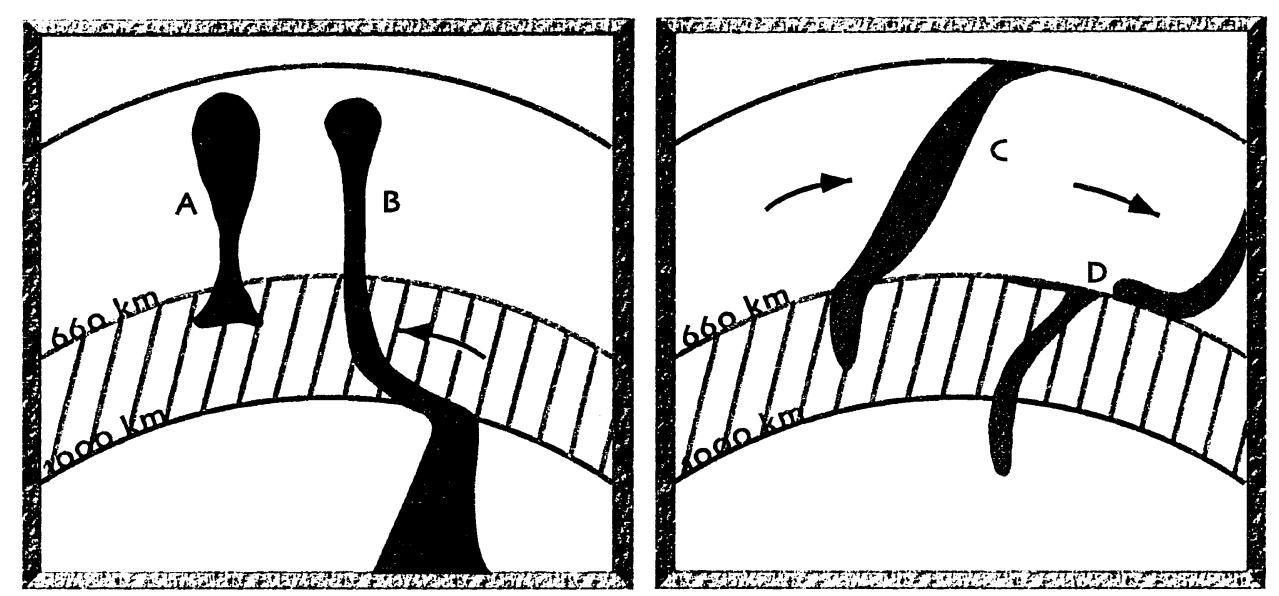

Fig. 11. Schematic diagram summarizing the different mesoscale features involving both upwelling (A and B) and downwelling (C and D) features. Plume deflection may be facilitated by the presence of a second low viscosity zone, which induces a channel flow. The hatched region marks the locale of interest, right below the proverbial $660 \mathrm{~km}$ discontinuity.

In Fig. 9 we show two snapshots, which reveal the smallscale downwellings (with $T=0.3$ ) penetrating into the second asthenosphere. One notices that the same temperature ( $T=0.3$ ) can be associated with an upper-mantle plume or with a downwelling into the shallow part of the lower mantle. This phenomenon reflects the nature of the internal thermal boundary layer developed at $660 \mathrm{~km}$ depth in certain regions. Some of these downwellings can merge in the second LVZ, to form a bigger downwelling, which then can penetrate into the lower mantle deeper than $1000 \mathrm{~km}$.

At times the secondary plume can erupt in a spectacular fashion, as shown by the snapshots in Fig. 10, taking from different angles. We note especially that the large plume head produced by this burst has a diameter near the surface, which exceeds $2000 \mathrm{~km}$. This type of large-scale plume eruption is not due to deep mantle plumes, but rather is caused by an instability in the transition zone from an earlier flushing event. This process sent forth a large pool of cold material with $T=0.3$ into the deep lower mantle. In this sense, the origin of this plume instability is different from the secondary instability shown above for the spherical-shell model (see Figs. 2 to 6), which does not have a low viscosity zone nor a phase transition at $1000 \mathrm{~km}$ depth for trapping both cold and hot material there. We note that the cylindrical form of the 3-D instability enables more hot material to be brought up than by the sheet-like upwellings in 2-D models (Steinbach and Yuen, 1997). Thus the potential presence of a second LVZ and a deeper phase transition would generate a whole new suite of multiscale features in the mid-mantle with dynamical consequences for both the upper-mantle and deep lower-mantle. Recently we have found that the same phenomenon of plumes developing right under the $660 \mathrm{~km}$ phase change can also take place just with the presence of the second asthenosphere (Cserepes and Yuen, 1998) and without the phase transition at $1000 \mathrm{~km}$.

We have provided a detailed visualization display of the dynamical features found in mantle convection with phase transitions and different viscosity structures. Previous studies of 3-D mantle convection with phase transitions (Honda et al., 1993; Tackley et al., 1993, 1994; Yuen et al., 1994a) did not focus into the dynamics at the transition zone because of the coarser spatial resolution than the fine grid employed here for both the 2-D and 3-D calculations. In these previous models (e.g. Tackley et al., 1993; Honda et al., 1993) no massive gushing events were found because there were no second low viscosity zones imposed. The presence of a low viscosity zone under the $660 \mathrm{~km}$ boundary offers such possibilities. Indeed there is a window in the parameter space of Rayleigh number in which such massive plume events coming from the shallow lower mantle are feasible, as this phenomenon was not detected previously by Cserepes and Yuen (1997), who have imposed a second low-viscosity zone into their model. Increasing the magnitude of the viscosity well in the second asthenosphere would enhance the likelihood for producing these types of shallow lower-mantle plumes. We emphasize here that sufficient grid points, at least 30 to 40, are required in the transition zone for detecting the multiscale secondary instabilities arising from an internal thermal boundary layer in a layered convective system with a second low viscosity zone at high Rayleigh number.

In Fig. 11 we summarize from our 2D and 3D models the possible mesoscale dynamical features, which may develop in the mantle between 660 and $1000 \mathrm{~km}$ depth because of the complex viscosity structure. First, secondary plumes (A) can be readily produced at the $660 \mathrm{~km}$ discontinuity. Second, some lower mantle plumes (B) can be deflected under $660 \mathrm{~km}$ and emerge into the upper mantle some distance away from the lower mantle plume. In this regard, the channel flow promoted by the second low viscosity zone helps to deflect the lower mantle plume passing through these depths. There are two types of downwellings. The first kind (C) cannot penetrate deeper than $1000 \mathrm{~km}$ because of the horizontal channeling flow in the second asthenosphere and the blocking effect from the potential $1000 \mathrm{~km}$ phase transition. On the other hand, some other cold downwellings (D) can merge and become strong enough to penetrate into the deep lower mantle. 


\section{Discussion and Closing Remarks}

Today we are at the crossroads in our understanding of the nature of the transition zone and the dynamical consequences. The traditional idea of an intrinsic and fundamentally dominating boundary at the $660 \mathrm{~km}$ discontinuity is now being questioned from many standpoints, from geochemistry, seismology, mineral physics, and the inversion of geoid anomalies. The nature of mantle flows across the transition zone is particularly sensitive to the viscosity structure and chemical stratification in the region some several hundred kilometers below the $660 \mathrm{~km}$ phase boundary. This is an area, not much touched upon, up to now, by convection modellers. With the 2-D model we have shown the dynamical effects due to the viscosity contrast across the $660 \mathrm{~km}$ phase boundary. With the 3-D model we have studied the influences from the presence of a low viscosity zone and an additional weaker endothermic phase change at $1000 \mathrm{~km}$ depth. Both models indeed reveal the wide complexity to be encountered in both the upwelling flows and the descending currents.

The 2-D axisymmetric model has demonstrated that the upwellings can be bent by their shear interaction with the endothermic phase transition at $660 \mathrm{~km}$ and that diapiric upwellings can develop some distance away from the lowermantle large plume. Recent high-resolution tomographic reconstruction by Bijwaard et al. (1998) and Bijwaard and Spakman (1998) have indeed revealed the bent nature of the plume in the lower mantle under Iceland with a diameter of around $500 \mathrm{~km}$. Furthermore, their images show that the upwellings in the upper mantle do not align exactly with the lower-mantle plume.

A low-viscosity zone under the $660 \mathrm{~km}$ discontinuity favors the formation of many plumes with origins in the transition zone, because of its tendency to cause decoupling between the upper and deep mantle circulation, which results in the formation of an internal thermal boundary layer. In a system with a large surface Rayleigh number but an increasing viscosity in the lower mantle, the plumes developed in the lower mantle are large and stationary and they may be deflected at the $660 \mathrm{~km}$ discontinuity. Secondary plumes may then arise upward from the transition zone at some horizontal distance away from the lower-mantle plume. In some sense, the second low viscosity zone serves as a thoroughfare under the $660 \mathrm{~km}$ discontinuity for transporting hot material laterally in a rapid fashion. This scenario accords well with the ideas of plume tectonics based on geological arguments (Maruyama, 1994). Mantle plumes, which originate at the thermal boundary layer associated with the $660 \mathrm{~km}$ discontinuity, can entrain shallow lower mantle material into its central portion (see A in Fig. 11). Geochemical data (Fitton et al., 1997) have argued for the Icelandic plume to have origins at the transition zone. Geochemical evidence, especially that derived from noble gases, favors some type of layered convection but one in which the layers are not completely isolated (Hofmann, 1997). The history of deep mantle plume activities may well have been episodic and linked to the flushing event involving an unusually large instability as in the Cretaceous period (Maruyama, 1994; Yuen et al., 1994b). The question concerning the depth of origin of hot upwellings can be posed for the Hawaiian plume in the upper mantle, whether, it may, in fact, be connected to the lower mantle upwelling in the central Pacific (Maruyama, 1994), which from recent seismic analysis displays distinct signatures of partial melting at its base (Garnero and Helmberger, 1996; Helmberger et al., 1998).

It has been debated whether or not a plume, originating spontaneously by an instability in the $660 \mathrm{~km}$ thermal boundary layer, could be as large and vigorous as the Iceland plume appeared to be at its initiation at $62 \mathrm{Ma}$ (Chalmers et al., 1995). An area with a diameter of around $2000 \mathrm{~km}$, stretching from west Greenland to northwest Scotland, has been inferred for the rapid eruption of picrite, implying a mantle plume up to a couple hundred of degrees hotter than the surrounding. The mushroom head of the megaplume burst shown in Fig. 10 has a diameter of well over $2000 \mathrm{~km}$. Alternatively, ultrafast plumes (Larsen and Yuen, 1997) can also explain the synchroneity of the volcanism caused by the enormous Icelandic plume around $63 \mathrm{Ma}$ ago. Such a large dimension of the plume would be not possible from steady-state boundary layer predictions (Olson and Corcos, 1980) or from starting plume models (e.g. Griffiths and Campbell, 1990), where there is no available reservoir of trapped material. This megaplume burst is a fluid-dynamical manifestation of what is known in physics as a threshold process, as found in the percolation phenomenon (e.g. Stauffer and Aharony, 1991). This non-linear process causes a sudden upward discharge of the accumulated hot material, which has been trapped in the region between the $660 \mathrm{~km}$ discontinuity and the base of the second asthenosphere. One can regard this second low-viscosity zone as a potentially important geochemical reservoir, sampled by such a gushing event. This spectacular outpouring phenomenon is intrinsically nonlinear in nature and is somewhat akin to the flushing instability involving massive amounts of cold material descending into the lower mantle (Tackley et al., 1993; Honda et al., 1993; Solheim and Peltier, 1994). A two-dimensional Cartesian version of this massive upwelling of hot material from the lower to the upper mantle has also been found by Steinbach and Yuen (1998). In this regard, the second asthenosphere plays the analogous role of a non-linear capacitor in storing up hot lower-mantle material, which is poised for a rapid takeoff upwards upon an excitation by an external perturbation, either by deep mantle plumes or by nearby cold downwellings able to sink into deep lower mantle. More work is still needed to delve into this tantalizing issue of the underlying physical mechanism for dispatching large amounts of hot material from the shallow lower mantle to the upper mantle. Important effects, such as internal heating and lateral variations of the viscosity, should be studied in the future.

In the Pacific region the upper mantle and transition zone under the Ontong-Java plateau offer an excellent venue for such a long-term study of the thermal-mechanical structure in the top portion of the lower mantle. The observation sites of the OHP project can be gainfully employed for this purpose. Both the seismic and electrical conductivity studies will be extremely useful in this endeavor of studying the mid-mantle structure in the western Pacific, between 660 and around $1200 \mathrm{~km}$ depth.

Acknowledgments. D. A. Yuen would like to thank the organizing 
committee of OHP for inviting him to the OHP symposium. Stimulating discussions about megaplumes and internal thermal boundary layers with Shige Maruyama, Tetsu Seno, Motoyuki Kido and Walter Mooney are gratefully acknowledged. Comments from the three reviewers and Alex Forte have helped to improve this manuscript. He also thanks Jerry Schubert for a conversation about plumes from the $660 \mathrm{~km}$ discontinuity and Josh Collins for technical assistance. This research has been supported by the Hungarian National grant OTKA T015966, the geophysics program of the National Science Foundation and the J.S.P.S. Brigit A. Schroeder thanked E.R.I., Univ. Tokyo for support during her visit to Japan in 1996 and N.S.F. for a REU award in summer of 1997.

\section{References}

Allegre, C. J., Limitation on the mass exchange between the upper and lower mantle: the evolving convection regime of the Earth, Earth Planet. Sci. Lett., 150, 1-6, 1997.

Allegre, C. J. and D. L. Turcotte, Geodynamic mixing in the meso-sphere boundary layer and the origin of oceanic islands, Geophys. Res. Lett., 12, 207-210, 1985.

Bercovici, D. and J. Mahoney, Double flood basalts and plume head separation at the 660-kilometer discontinuity, Science, 266, 1367-1369, 1994.

Bijwaard, H. and W. Spakman, Tomographic evidence for a narrow whole mantle plume below Iceland, Earth Planet. Sci. Lett., 1998 (in press).

Bijwaard, H., W. Spakman, and E. R. Engdahl, Closing the gap between regional and global travel time tomography, J. Geophys. Res., 1998 (in press)

Birch, F., The earth's mantle: elasticity and constitution, Trans. Am. Geophys. Union, 35, 79-85, 1954.

Breuer, D. and T. Spohn, Possible flush instability in mantle convection at the Archaean-Proterozoic transition, Nature, 378, 608-610, 1995.

Breuer, D., D. A. Yuen, and T. Spohn, Phase transitions in the Martian mantle: Implications for partially layered convection, Earth Planet. Sci. Lett., 148, 457-469, 1997.

Brunet, D. and P. Machetel, Large-scale tectonic features induced by mantle avalanches with phase, temperature and pressure lateral variation of viscosity, J. Geophys. Res., 103, 4929-4945, 1998.

Bunge, H.-P. and M. A. Richards, The origin of large scale structure in mantle convection: effects of plate motions and viscosity stratification, Geophys. Res. Lett., 23, 2987-2990, 1996.

Cadek, O., H. Ciskova, and D. A. Yuen, Can long-wavelength dynamical signatures be compatible with layered convection?, Geophys. Res. Lett., 24, 2091-2094, 1997.

Castle, J. C. and K. C. Creager, Topography of the $660-\mathrm{km}$ seismic discontinuity beneath Izu-Bonin: Implications for tectonic history and slab deformation, J. Geophys. Res., 1998 (in press).

Chalmers, J. A., L. M. Larsen, and L. Pedersen, Widespread Paleocene volcanism around the northern Atlantic and Labrador Sea: evidence for a large, hot, early plume head, J. Geol. Soc., London, 152, 965-969, 1995.

Chopelas, A. and R. Boehler, Thermal expansivity of the lower mantle, Geophys. Res. Lett., 19, 1983-1986, 1992.

Christensen, U. R., The influence of trench migration on the slab penetration into the lower mantle, Earth Planet. Sci. Lett., 140, 27-39, 1996.

Christensen, U. R. and D. A. Yuen, Layered convection induced by phase transitions, J. Geophys. Res., 90, 10,291-10,300, 1985.

Cizkova, H. and O. Cadek, Effect of a viscosity interface at $1000 \mathrm{~km}$ depth on mantle convection, Studia geoph. et geod., 41, 297-306, 1997.

Cserepes, L. and D. A. Yuen, Dynamical consequences of mid-mantle viscosity stratification on mantle flows with an endothermic transition, Geophys. Res. Lett., 24, 181-184, 1997.

Cserepes, L. and D. A. Yuen, Mantle plumes developing in a second low viscosity zone below the $660 \mathrm{~km}$ discontinuity, A.G.U. abstract, Fall meeting, 1998

Cserepes, L., M. Rabinowicz, and C. Rosemberg-Borot, Three-dimensional infinite Prandtl number convection in one or two layers with implications for the Earth's gravity field, J. Geophys. Res., 93, 12,009-12,025, 1988.

Cserepes, L., D. A. Yuen, and B. A. Schroeder, Effects of the mid-mantle viscosity and phase-transition structure on 3-D mantle convection, Phys. Earth Planet. Inter, 1998 (submitted).

Davies, G. F., Penetration of plates and plumes through the mantle transition zone, Earth Planet. Sci. Lett., 133, 507-516, 1995.

Fitton, J. G., A. D. Saunders, M. J. Norry, B. S. Hardarson, and R. N. Taylor, Thermal and chemical structure of the Iceland plume, Earth Planet. Sci. Lett., 153, 197-208, 1997.
Fornberg, B., High-order finite differences and the pseudospectral method on staggered grids, S.I.A.M., J. Numer. Anal., 27, 904-918, 1990.

Forte, A. M., R. L. Woodward, and A. M. Dziewonski, Joint inversions of seismic and geodynamic data for models of three-dimensional mantle heterogeneity, J. Geophys. Res., 99, 21875-21897, 1994.

Garnero, E. J. and D. V. Helmberger, Seismic detection of a thin laterally varying boundary layer at the base of the mantle beneath the centralPacific, Geophys. Res. Lett., 23, 977-980, 1996.

Griffiths, R. W. and I. H. Campbell, Stirring and structure in mantle starting plumes, Earth Planet. Sci. Lett., 99, 66-78, 1990.

Griffiths, R. W., R. I. Hackney, and R. D. van der Hilst, A laboratory investigation of effects of trench migration on the descent of subducted slabs, Earth Planet. Sci. Lett., 133, 1-17, 1995.

Guillou-Frottier, L., J. Buttles, and P. Olson, Laboratory experiments on the structure of subducted lithosphere, Earth Planet. Sci. Lett., 133, 19-34 1995.

Helmberger, D. V., L. Wen, and X. Ding, Seismic evidence that the source of the Iceland hotspot lies at the core-mantle boundary, Nature, 396, 251-255, 1998.

Hofmann, A. W., Mantle geochemistry: the message from oceanic volcanism, Nature, 385, 219-229, 1997.

Honda, S., D. A. Yuen, S. Balachandar, and D. Reuteler, Three-dimensional instabilities of mantle convection with multiple phase transitions, Science, 259, 1308-1311, 1993.

Irifune, T., T. Koizumi, and J. Ando, An experimental study of the garnetperovskite transformation in the system $\mathrm{MgSiO}_{3}-\mathrm{Mg}_{3} \mathrm{Al}_{2} \mathrm{Si}_{3} \mathrm{O}_{12}$, Phys Earth Planet. Inter., 96, 147-157, 1996.

Jarvis, G. T. and D. P. McKenzie, Convection in a compressible fluid with infinite Prandtl number, J. Fluid Mech., 96, 515-583, 1980.

Karato, S., Seismic anisotropy in the deep mantle, boundary layers and the geometry of mantle convection, Pure Appl. Geophys., 151, 565-587, 1998 .

Kawakatsu, H. and F. Niu, Seismic evidence of a 920-km discontinuity in the mantle, Nature, 371, 301-305, 1994.

Kesson, S. E., J. D. Fitz Gerald, J. M. G. Shelley, and R. L. Withers, Phase relations, structure and crystal chemistry of some aluminous silicate perovskites, Earth Planet. Sci. Lett., 134, 187-201, 1995.

Kido, M. and O. Cadek, Inferences of viscosity from the oceanic geoid: Indication of a low viscosity zone below the $660-\mathrm{km}$ discontinuity, Earth Planet. Sci. Lett., 151, 125-138, 1997.

Kido, M., D. A. Yuen, O. Cadek, and T. Nakakuki, Mantle viscosity derived by genetic algorithm using oceanic geoid and seismic tomography for whole-mantle versus blocked-flow situation, Phys. Earth Planet. Inter. 107, 307-326, 1998.

Larsen, T. B. and D. A. Yuen, Ultra-fast upwelling bursting through the upper mantle, Earth Planet. Sci. Lett., 146, 393-400, 1997.

Larsen, T. B., D. A. Yuen, J. Moser, and B. Fornberg, A higher-order finitedifference method applied to large Rayleigh number mantle convection, Geophys. Astrophys. Fluid Dyn., 84, 53-83, 1997.

Le Stunff, Y., C. W. Wicks, and B. Romanowicz, P'P' precursors under Africa: evidence for mid-mantle reflectors, Science, 270, 74-77, 1995.

Liu, M., D. A. Yuen, W. Zhao, and S. Honda, Development of diapiric structures in the upper mantle due to phase transitions, Science, 252, 1836-1839, 1991.

Maruyama, S., Plume tectonics, J. Geol. Soc. Japan, 100, No. 1, 24-49, 1994

Montagner, J. P. and B. L. N. Kennett, How to reconcile body-wave and normal-mode reference earth models, Geophys. J. Int., 125, 229-248, 1996.

Nakakuki, T., D. A. Yuen, and S. Honda, The interaction of plumes with the transition zone under continents and oceans, Earth Planet. Sci. Lett., 146, 379-392, 1997.

Niu, F. and H. Kawakatsu, Depth variation of the mid-mantle seismic discontinuity, Geophys. Res. Lett., 24, 429-432, 1997.

O'Neill, B. and R. Jeanloz, $\mathrm{MgSiO}_{3}-\mathrm{FeSiO}_{3}-\mathrm{Al}_{2} \mathrm{O}_{3}$ in the Earth's lower mantle: Perovskite and garnet at $1200 \mathrm{~km}$ depth, J. Geophys. Res., 99 , 19,901-19,915, 1994

Obayashi, M., T. Sakurai, and Y. Fukao, The 3-D structure of the mantle from travel time inversion, J. Geography, 104, No. 7, 934-940, 1995 (in Japanese).

Olbertz, D., M. J. R. Wortel, and U. Hansen, Trench migration and subduction zone geometry, Geophys. Res. Lett., 24, 221-224, 1997.

Olson, P. L. and G. Corcos, A boundary layer model for mantle convection with surface plates, Geophys. J. R. astr. Soc., 62, 195-219, 1980.

Quinn, K. J. and M. K. McNutt, Inversion of topography and geoid for 
mantle viscosity beneath the Pacific plate using genetic algorithms, $J$. Geophys. Res., 1998 (submitted).

Ravine, M. A. and J. Phipps-Morgan, Inversion for radial mantle viscosity with a layered constraint: a better fit to dynamic topography?, EOS Trans. A.G.U., 77, No. 46, F721, 1996.

Ribe, N. M., On the relation between seismic anisotropy and finite strain, $J$. Geophys. Res., 97, 8737-8747, 1992.

Riedel, M. R. and S. Karato, Grain-size evolution in subducted oceanic lithosphere associated with the olivine-spinel transformation and its effects on rheology, Earth Planet. Sci. Lett., 148, 27-44, 1997.

Ringwood, A. E., Phase transformations in descending plates: implications for mantle dynamics, basalt petrogenesis, and crustal evolution, J. Geology, 90, 611-643, 1982.

Solheim, L. P. and W. R. Peltier, Avalanche effects in phase transition modulated thermal convection: A model of the Earth's mantle, J. Geophys. Res., 99, 6997-7018, 1994.

Stauffer, D. and A. Aharony, Introduction to Percolation Theory, Second Edition, Taylor and Francis, London, 1991.

Steinbach, V. and D. A. Yuen, Effects of depth-dependent properties on the thermal anomalies produced in flush instabilities from phase transitions, Phys. Earth Planet. Inter, 86, 165-183, 1994.

Steinbach, V. and D. A. Yuen, The influences of temperature- and pressuredependent lower-mantle rheology on the interaction of upwellings with phase transitions, Phys. Earth Planet. Inter, 103, 85-100, 1997.

Steinbach, V. and D. A. Yuen, The influences of surface temperature on upwellings in planetary convection with phase transitions, Earth Planet. Sci. Lett., 160, 1998.

Steinbach, V., U. Hansen, and A. Ebel, Compressible convection in the earth's mantle: a comparison of different approaches, Geophys. Res. Lett., 16, 633-635, 1989.

Steinbach, V., D. A. Yuen, and W. Zhao, Instabilities from phase transitions and the timescales of mantle evolution, Geophys. Res. Lett., 20, 1119$1122,1993$.

Tackley, P. J., D. J. Stevenson, G. A. Glatzmaier, and G. Schubert, Effects of an endothermic phase transition at $670 \mathrm{~km}$ depth on spherical mantle convection, Nature, 361, 699-704, 1993.

Tackley, P. J., D. J. Stevenson, G. A. Glatzmaier, and G. Schubert, Effects of multiple phase transitions in a three dimensional spherical model of convection in Earth's mantle, J. Geophys. Res., 99, 15,877-15,902, 1994.

Thompson, P. F. and P. J. Tackley, Generation of mega-plumes from the coremantle boundary in a compressible mantle with temperature-dependent viscosity, Geophys. Res. Lett., 25, 1999-2002, 1998.

Travis, B., P. Olson, and G. Schubert, The transition from two-dimensional to three-dimensional planforms in infinite-Prandtl-number thermal convection, J. Fluid Mech., 216, 71-91, 1990.

Tschauner, O., Stabilitaet und chemische Eigenschaften von Ni, Co: (Mg, $\mathrm{Fe}) \mathrm{SiO}_{3}$-Perowskit, Ph.D. Thesis, Univ. Mainz, 1997.

Tschauner, O., A. Zerr, S. Specht, R. Boehler, and H. Palme, Partitioning of nickel and cobalt between metal and silicate perovskite up to $80 \mathrm{GPa}$, Nature, 1998 (in press).

van Keken, P. E. and D. A. Yuen, Dynamical influences of high viscosity in the lower mantle induced by the steep melting curve of perovskite: Effects of curvature and time dependence, J. Geophys. Res., 100, B8, 15,233-15,248, 1995.

van Keken, P. E., D. A. Yuen, and A. P. van den Berg, Pulsating diapiric flows: consequences of vertical variations of mantle creep laws, Earth Planet. Sci. Lett., 112, 179-194, 1992.

Vinnik, L., S. Chevrot, and J.-P. Montagner, Evidence for a stagnant plume in the transition zone, Geophys. Res. Lett., 24, 1007-1010, 1997.

Wen, L. and D. V. Helmberger, Ultra-low velocity zones near the core-mantle boundary from broadband PKP precursors, Science, 279, 1701-1703, 1998.

White, R. and D. P. McKenzie, Magmatism in rift zones: the generation of volcanic continental margins and flood basalts, J. Geophys. Res., 94, 7685-7729, 1989

Widiyantoro, S., Studies of seismic tomography on regional and global scale, Australian National University, 246 pp., 1997.

Widiyantoro, S. and R. D. van der Hilst, Structure and evolution of lithospheric slab beneath the Sunda Arc, Science, 271, 1566-1570, 1996.

Yuen, D. A., D. M. Reuteler, S. Balachandar, V. Steinbach, A. V. Malevsky, and J. L. Smedsmo, Various influences on three-dimensional mantle convection with phase transitions, Phys. Earth Planet. Inter., 86, 185-203, 1994a.

Yuen, D. A., O. P. Cadek, R. Boehler, J. Moser, and C. Matyska, Large cold anomalies in the deep mantle and mantle instability in the Cretaceous, Terra Nova, 6, 238-245, 1994b.

Zhang, S. and D. A. Yuen, Various influences on plumes and dynamics in time-dependent, compressible, mantle convection in 3-D spherical shell, Phys. Earth Planet. Inter., 94, 241-267, 1996.

Zhou, H.-W., A high-resolution P wave model for the top $1200 \mathrm{~km}$ of the mantle, J. Geophys. Res., 101, 27,791-27,810, 1996.

D. A. Yuen (e-mail: davey@banzai.msi.umn.edu), L. Cserepes, and B. A. Schroeder 